\title{
Successive discrimination reversal (SDR) performances of four avian species on a brightness discrimination task
}

Four avian species which had previously received extensive training on a spatial successive reversal task, were given 19 reversals of a brightness discrimination. Analysis of errors across reversals reveal inter-species performance differences paralleling those obtained on a spatial reversal task.

Previous research has demonstrated that both closely and remotely related avian species (Gossette, Gossette, \& Riddell, 1966) and closely related New World Monkeys (Gossette \& Inman, 1966) display inter-species differences on a spatial successive reversal task consistent with their taxonomic ordering. However, it is uncertain whether such differences reflect primarily the sensitivity of SDR methodology, or the choice of a spatial habit reversal for interspecies comparisons. To provide information bearing upon the generality of SDR methodology as a procedure for calibrating inter-species differences, selected avian species, previously compared on a spatial reversal task, were tested on a brightness reversal task.

\section{Subjects and Apparatus}

All Ss in this experiment had previously received 29 reversals of a spatial habit in the same apparatus as described below. Four species were represented: three White Leghorn chickens, two Yellow-head parrots (Amazona ochrocephala), three Greater Hill Mynas (Gracula religiosa) and three Red-billed Blue Magpies (Urocissa occipitalis). Measurement of reversal performances was made in a formboard box previously described (Gossette, Gossette, \& Riddell, 1966). The only modification was the replacement of the round white stimulus blocks employed in the spatial reversal by a pair of black-white stimulus blocks. Procedure

For the initial brightness discrimination problem, reinforcement consisting of a preferred food item for each species was contingent upon responding to the black block. Since all Ss had previously been trained to respond to white blocks on a spatial basis in the preceding experiment, a high level of responding to the white block transferred to the initial blackwhite problem. Position of the black block was randomly shifted from left to right with the restrictions that it should not remain in either position for more than four successive trials, and that within each session, each position should be equally represented. Daily 20-trial sessions were continued until a criterion of 18 correct responses to the black block during a given session had been achieved. On the next test day, the reinforcement contingencies were again reversed, with food under the white block. Training proceeded as in Problem 1 until criterion performance was again established. In this manner, 20 reversals of a brightness habit were attached for each S. Non-correction was employed throughout.

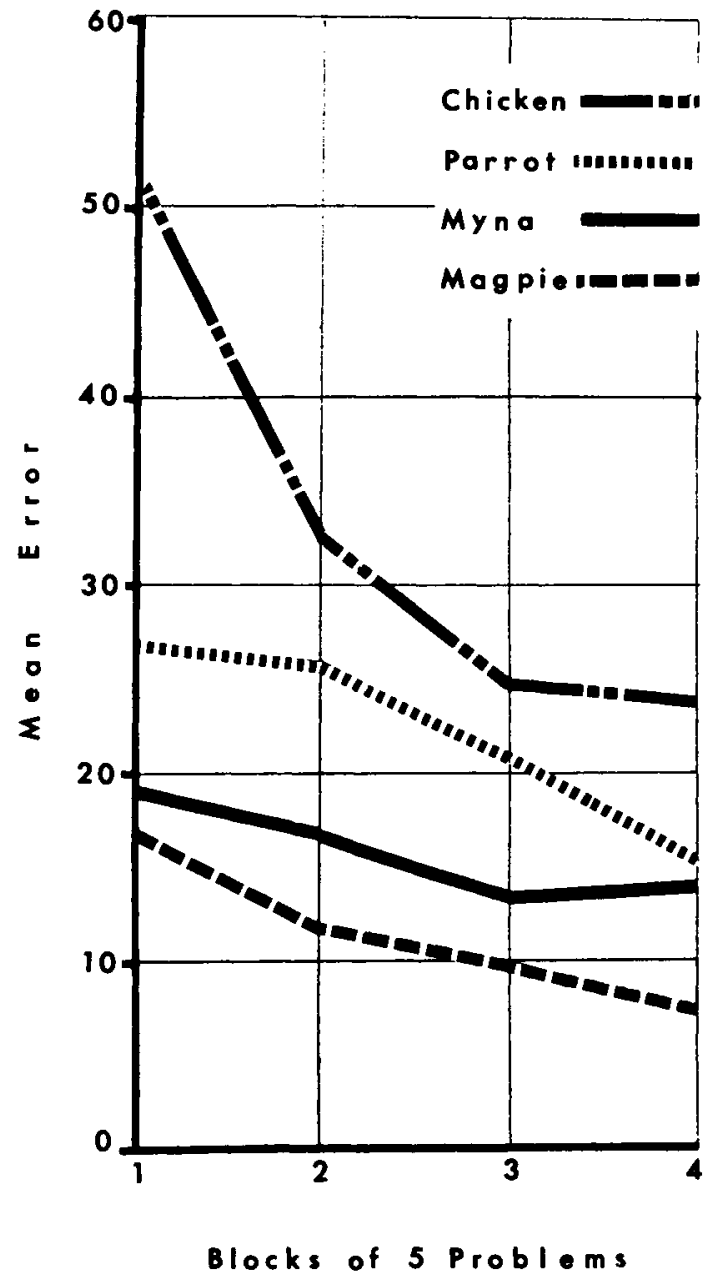

Fig. 1. Mean error per problem in blocks of five problems for four avian species. 
Table 1. Mean Error and Range of Errors for Four Avian Species.

\begin{tabular}{lllll} 
& Magpie & Myna & Parrot & Chicken \\
\hline Mean Error & 229.2 & 316.7 & 443.0 & 662.3 \\
Range & $172-271$ & $246-361$ & $440-446$ & $510-822$ \\
\hline
\end{tabular}

\section{Results and Discussion}

The principal response measure selected for description was the number of errors across reversal problems. The mean total errors are shown in Table 1. As can be seen the group means are clearly separated, with only one instance of an overlap of individual total errors, e.g., Magpie and Myna. The plots of errors across problems, Fig. 1, reveal consistent separation.

These functions closely parallel those previously reported (Gossette, Gossette, \& Riddell, 1966). Two major differences, however, are apparent. The absolute scores are higher, indicating that despite the extensive preceding training on a spatial reversal task, the brightness reversal remains more difficult.
More importantly, however, it appears that with increasing task difficulty, there is an amplification of inter-species performance differences, particularly for more closely related species. Thus it is tentatively suggested that one way to improve the sensitivity of SDR as an instrument for calibrating interperformance differences would be to increase the difficulty of the reversal task. This feature is currently being investigated with mammalian species in our laboratory.

\section{References}

Gossette, R. L., Gossette, M. F., \& Riddell, W. Comparisons of successive discrimination reversal performances among closely and remotely related avian species. Anim. Behav., 1966, 14, 560-564.

Gossette, R. L., \& Inman, N. Comparison of spatial successive discrimination reversal performances in two groups of New World monkeys. Percept. mot. Skills, 1966, 23, 169-170.

\section{Notes}

1. This work was supported in part by NIMH grant MH11138-01. 2. We wish to thank Miss Gale Krause for her assistance in obtaining some of the data described in the report. 